\title{
Phenotypic characterization of the resistance of Salmonella - Shigella isolates to colistin and detection of $\mathrm{mcr} 1 / 2$ genes
}

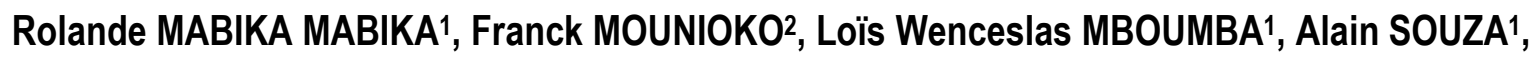
Jean Fabrice YALA ${ }^{* 1}$

${ }^{1}$ Laboratoire de Biologie Moléculaire et Cellulaire, équipe de Microbiologie (LABMC), Unité de recherche Agrobiologie, Université des Sciences et Techniques de Masuku (USTM), BP 067 Franceville, Gabon.

2Laboratoire d'Écologie Vectorielle, LEV, Institut de Recherche en Ecologie Tropicale (IRET), BP 13354, Libreville, Gabon

${ }^{*}$ Corresponding Author : Jean Fabrice YALA

Laboratoire de Biologie Moléculaire et Cellulaire ; Équipe de Microbiologie, Université des Sciences et Techniques de Masuku (USTM), BP 067 Franceville, Gabon. Correspondent E. mail: (yalalajeanfabrice@gmail.com) Tel: +241 66.18 .84 .88

Original submitted in on $15^{\text {th }}$ October 2020. Published online at www.m.elewa.org/journals/ on 31 st December 2020 https://doi.org/10.35759/JABs.156.6

\begin{abstract}
Objective: Colistin is one of the latest line of therapeutics used in the management of infections due to multiresistant Gram-negative bacteria. The current emergence of colistin resistance, in particular through the mediation of plasmid resistance genes (mcr1 and mcr2) in intestinal bacteria is a worldwide concern. The objective of this study is to evaluate the sensitivity of Salmonella and Shigella strains to colistin and the detection of $m c r 1$ and $m c r 2$ genes within these strains.

Methodology and Results: The colistin sensitivity profile of 30 Salmonella strains and 5 Shigella strains was determined using the Minimum Inhibitory Concentrations in liquid medium of Mueller Hinton and the results were interpreted in accordance with the standards of the European Committee on Antimicrobial Susceptibility Testing Epidemiological cut-off 2020 version 10.0. Finally, the mcr1 and mcr2 genes were detected by a conventional PCR. Overall, a phenotypic resistance rate of $20 \%$ was recorded for Salmonella-Shigella pathogens, with a frequency of $17.1 \%$ for Salmonella and $2.9 \%$ for Shigella. Molecular screening of these isolates revealed a lack of detection of the $m c r 1$ and $m c / 2$ genes in their genetic heritage.

Conclusion and application of results: this study shows that Salmonella and Shigella strains are resistant to colistin, however the mcr 1 and 2 genes have not been amplified. To this end, the rational use of colistin must be applied in the human and animal field in order to curb the increase and spread of resistance to this molecule.
\end{abstract}

Keywords: Colistin, Gabon, mcr, resistance, Salmonella-Shigella 


\section{INTRODUCTION}

Antimicrobial resistance is a topic of particular interest due to the widespread of serious infectious caused by enterobacteria such as, Escherichia, Salmonella, Shigella, Klebsiella, Enterobacter, Serratia, Proteus, Morganella and Yersinia (Dortetet al,, 2010). Among these enterobacteriaceae infections, Escherichia, Salmonella and Shigella cause severe forms of the digestive tract (e.g., gastroenteric) (Ayalu A et al., 2011; Lamberti et al., 2014). In addition, Salmonella is responsible for over 200 million cases of diarrhoea worldwide and over 3 million deaths. Whereas Shigella is responsible for over 650,000 deaths (Ayalu A et al., 2011). In this context, both Salmonella and Shigella represent a real worldwide concern, particularly in developing countries (Mohammadmahdi et al., 2020). $\beta$-lactams are the first-line molecules in the treatment of enterobacteriaceae infections due to their low toxicity and bactericidal potency (Robin, Gibold and Bonnet, 2012). However, the massive use of antibiotics has largely contributed to the emergence of enterobacteria resistance. In addition, several strains of enterobacteriaceae family are reported to have an extended spectrum of antibiotic resistance, in part due to the acquisition of genes of resistance and by their own resistance (Nordmann et al., 2012). Moreover, the production of $\beta$-lactam inactivating enzymes ( $\beta$-lactamases) contributed to the emergence and expansion of extended-spectrum $\beta$-lactamase producing enterobacteriaceae (EBLSE) or carbapenemase that are known as multi-strain resistant (Cattoir, 2013; Doit, 2015). This multi-resistance has been also reported recently from Shigella isolates (Mohammadmahdi et al., 2020). The widespread of carbapenemase-producing Enterobacteriaceae limits the therapeutic approaches against serious infections caused by enterobacteria strains. This phenomenon is responsible of the significant reduction in the effectiveness of new molecules

\section{MATERIAL AND METHODS}

Bacterial strains: Salmonella and Shigella strains isolated from diarrheal faeces in children aged 0 to 5 years in the city of Koula-Moutou were screened in this study at the phenotypic and genotypic levels. available (Cattoir, 2013). To face this problem, colistin antibiotic has been proposed as the lastresort therapy against Enterobacteriaceae Producing Carbapenemase (ECP) infections (L. Dortet et al., 2016; Yi et al., 2019). However, the great adaptability of these bacteria also favoured the selection of colistin-resistant mutants (Zhang et al., 2018). Globally, the frequency of resistance to colistin remains relatively low although its impact is increasingly reported (Kim et al., 2019). The most common enterobacteria strains are from $E$. coli, Klebsiella pneumoniae and Enterobacter cloacae (Mezghani Maalej et al., 2012). Additionally, E. coli resistance rates were found between $0.1 \%$ to $2 \%$ in North America, $0.3 \%$ in Europe (Gales, Jones and Sader, 2011; L Dortet et al., 2016). Strains of Klebsiella spp showed rates of $1.8 \%, 1.5 \%, 2.1 \%$ and $0.8 \%$ respectively for North America, Europe, Latin America and Asia Pacific (Gales, Jones and Sader, 2011). In African areas, the few studies carried out in Nigeria, Egypt and Tunisia show extremely low prevalence of colistin resistance in enterobacteriaceae (L. Dortet et al., 2016). In Tunisia, strains of $E$. coli, K. pneumoniae and Enterobacter cloacae showed prevalence of resistance to colistin of $0.09 \%, 1.2 \%$ and $1.5 \%$, respectively (Mezghani Maalej et al., 2012). However, studies in Nigeria and Egypt did not identify any resistant strains (Adelowo et al., 2014; Hasanin et al., 2014). In Gabon, while little is known, however, a recent study from 20 isolates of $E$. coli from childhood diarrheal faeces showed $40 \%$ of resistance to colistin (Mabika Mabika et al., 2019; Yala et al., 2020). The main objective of this study is to evaluate the sensitivity of Salmonella and Shigella strains isolated from diarrheal faeces to colistin. This will be determined using their minimum inhibitory concentrations (MIC) and a conventional PCR for the detection of the mcr-1 and mcr-2 genes.

The strains of Salmonella genus consisted of 17 strains of Salmonella spp, 6 of Salmonella enterica, 4 of Salmonella Typhi and 3 of Salmonella Paratyphi A. The Shigella genus consisted of 3 strains of 
Shigella spp and 2 of Shigella sonnei. These strains have been cryopreserved in the strain library of the Laboratory of Cell and Molecular Biology at Masuku University of Science and Technology.

Evaluation of strain sensitivity to colistin: The determination of minimum inhibitory concentrations (MICs) was carried out using the reference method to characterize the phenotypes of Salmonella and Shigella with colistin. Briefly, geometric dilution ranges of reason 2 between $8 \mu \mathrm{g} / \mathrm{ml}-0.625 \mu \mathrm{g} / \mathrm{ml}$ were carried out and standardised inoculi were inoculated at $37^{\circ} \mathrm{C}$ for $18-24 \mathrm{~h}$ incubation. The MIC values of the European Committee on Antimicrobial Susceptibility Testing epidemiological cut-off (EUCAST ECOFF) were used for the interpretation of the MIC values obtained (EUCAST, 2020).

Detection of $m c r-1$ and $m c r-2$ genes in SalmonellaShigella strains: The search for the mcr-1 and mcr-
2 genes was carried out by conventional PCR on all 35 Salmonella-Shigella isolates. The specific primer sequences used were mcr-1 forward (5'AGTCCGTTTGTTCTTGTGGC-3'), mcr-1 reverse (5'-GGGGCTTGATGCTCACT-3'); mcr-2 forward (5'-CAAGTGTTGCGCAGTT-3') and mcr-2 reverse (5'-CAAGTGTGTGTTGCGCAGTT-3') (Zhang et al., 2018). The different amplification conditions were an initial denaturation at $95^{\circ} \mathrm{C}$ for 15 minutes followed by 35 denaturation cycles at $94^{\circ} \mathrm{C}$ for 15 seconds, a hybridization of $57^{\circ} \mathrm{C}$ of 30 seconds, an elongation of $68^{\circ} \mathrm{C}$ of 70 seconds and finally, the final elongation step at $72^{\circ} \mathrm{C}$ for 5 minutes. The amplicons obtained were separated on a $1.5 \%(\mathrm{~m} / \mathrm{v})$ agarose gel by electrophoresis and visualized under ultraviolet light.

\section{RESULTS}

Phenotypic prevalence of colistin resistance strains and of the $m c r-1$ and $m c r-2$ genes.

Table 1: Minimum inhibitory concentration values for strains of Salmonella and Shigella.

\begin{tabular}{|c|c|c|c|c|c|c|}
\hline & \multirow{3}{*}{$\begin{array}{l}\text { Effective } \\
\mathrm{N}\end{array}$} & \multicolumn{2}{|c|}{$\begin{array}{l}\text { Break point CMI } \\
\left(\mu g \cdot \mathrm{mL}^{-1}\right)\end{array}$} & \multirow{3}{*}{$\begin{array}{l}\text { Percentage of } \\
\text { resistance } \\
n(\%)\end{array}$} & \multicolumn{2}{|c|}{ Frequency of genes detected } \\
\hline & & Sensitivity & Resistant & & $m c r-1$ & $m c r-2$ \\
\hline & & $\begin{array}{l}\leq 2 \\
\mathrm{n}(\%)\end{array}$ & $\begin{array}{l}>2 \\
\mathrm{n}(\%)\end{array}$ & & $\mathrm{n}(\%)$ & n (\%) \\
\hline $\begin{array}{l}\text { Salmonella enterica } \\
\text { Salmonella } \\
\text { Paratyphi A } \\
\text { Salmonella spp } \\
\text { Salmonella Typhi } \\
\text { Total } \\
\text { Shigella sonnei } \\
\text { Shigella spp } \\
\text { Total } \\
\text { Global Total } \\
\end{array}$ & $\begin{array}{l}6 \\
3 \\
17 \\
4 \\
30 \\
2 \\
3 \\
5 \\
35 \\
\end{array}$ & $\begin{array}{l}5(83.3) \\
3(100.0) \\
13(76.5) \\
3(75.0) \\
24(80.0) \\
2(100.0) \\
2(66.7) \\
4(80.0) \\
28(80.0) \\
\end{array}$ & $\begin{array}{l}1(16.7) \\
- \\
4(23.5) \\
1(25.0) \\
6(20.0) \\
- \\
1(33.3) \\
1(20.0) \\
7(20.0) \\
\end{array}$ & $\begin{array}{l}1(2.9) \\
7(20.0)\end{array}$ & $\begin{array}{l}- \\
- \\
- \\
- \\
- \\
- \\
- \\
- \\
0(0.0) \\
\end{array}$ & $\begin{array}{l}- \\
- \\
- \\
- \\
- \\
- \\
- \\
- \\
0(0.0) \\
\end{array}$ \\
\hline
\end{tabular}

The results in Table I show that $80.0 \%$ of Salmonella and Shigella strains are sensitive to colistin compared to a resistance rate of $20.0 \%$. Specifically, $17.1 \%$ of Salmonella isolates are resistant to colistin, while only $2.9 \%$ of Shigella has this phenotype. Among the 4 species of Salmonella, Salmonella spp show the highest resistance rate
(23.5\%) followed by Salmonella Typhi $(25.0 \%)$ and Salmonella enterica (16.7\%). In contrast, only the Shigella spp strain is resistant to colistin (33.3\%) and all Shigella sonnei isolates are susceptible. In addition, molecular screening of the 35 target isolates revealed the absence of the mcr- 1 and $\mathrm{mcr}$ 2 genes, which are carried by the plasmids 


\section{DISCUSSION}

The main objective of this study was to evaluate the sensitivity of Salmonella and Shigella strains isolated from diarrheal faeces to colistin, using their MIC and a conventional PCR for the detection of the mcr-1 and mcr2 genes. Colistin is a cyclic cationic peptide that inhibits the growth of Gram-positive bacteria by disrupting the integrity of the outer membrane of these bacteria through the interaction of its positive electrostatic charges with the negative charges of the outer lipopolysaccharide membrane (Sun et al., 2009). The evaluation of the sensitivity of Salmonella and Shigella to colistin revealed an average prevalence $(20 \%)$ of resistance. These results are consistent with the work of (Morales et al., 2012), in which the authors showed that colistin resistance prevalence ranged from $10.52 \%$ to $21 \%$ for the genus Salmonella. for the genus Shigella, the authors showed a colistin resistance rate of $20-27 \%$ (Morales et al., 2012). However, these results are higher than those obtained in Europe and Asia where the authors found prevalence around 3\%(Gales et al., 2011; $\mathrm{L}$ Dortet et al., 2016). A recent study in Gabon revealed a high prevalence (40\%) of $E$. coli strains to colistin (Yala et al., 2020). The average rate of resistance of colistin resistance recorded in this study would be justified by the fact that colistin, although considered as the last line of defense against severe infections, is not yet misused abused in Gabon. Indeed, previous studies showed a relationship between the emergence of the colistin resistance gene $(m c r-1 / 2)$ and the overuse of colistin in the veterinary field (L. Dortet et al., 2016). This low use in rural areas could be an outcome of the limited access to colistin or polymixins for treatment of patients ( $\mathrm{L}$. Dortet et al., 2016). In addition, this could also be correlated with the small sample sizes of this study. Clearly, it has been shown that the overall number of strains tested could potentially impact the prevalence of antimicrobial resistance (Frye and Jackson, 2013). As a major component of the outer membrane of Gramnegative bacteria, LPS is the primary target of polymixins. Colistin resistance could be justified by the addition of positive charges to lipid, which is a component of the LPS, since these covalent changes in the lipid $A$ fraction by cationic substitution are the most common mechanism of colistin resistance by enterobacteriaceae (Kim et al., 2019). These changes in the charges of lipid $A$ lead to a reduction in the negative charge and consequently, a decrease in affinity or electrostatic interaction with colistin. On the other hand, these modifications of lipid $A$ by phosphoethanolamine transferase ( $p E t N)$ can be encoded by an Epta chromosomal gene (pmrC) or a plasmid gene, $\mathrm{mcr}$ (Nang et al., 2019). Furthermore, the modification of lipid A by 4-amino-4-deoxy-L-arabinose (L-Ara4n) is due to an exclusively chromosomal arnT (pmrk) gene (Nang et al., 2019). Indeed, it has been shown in the literature that cationic sugars such as L-Ara4n at lipid A in S. enterica reduce the negative charge of the outer membrane (Zhang et al., 2019). In addition, resistance in Salmonella and Shigella strains may be a consequence of specific mutations in the pmrAB and phoPQ genes (Kim et al., 2019). In addition to the changes in lipid $A$ by the addition of phosphate, phosphoethanolamine (pEtN) or 4-amino4-deoxy-L-arabinose (L-Ara4n) groups, some studies highlight the deacylation or hydroxylation of lipid chains (L. Dortet et al., 2016). Other studies highlighted also that specific mutations in two-component systems such as Pmrab and Phopq and their regulators Mgrb and Pmrd are associated with colistin resistance in Enterobacteriaceae, including Klebsiella pneumoniae, $\mathrm{K}$. aerogenes and Salmonella Enterica, as well as $P$. aeruginosa and $A$. baumanni (Poirelet al., 2017). The resistance observed in this study could be due to the acquisition of the plasmid mor genes. Indeed, enterobacteriaceae have a great ability to easily acquire genetic material by horizontal inter- and intra-species transfer, the process of which most often involves mobile genetic elements and particularly concerns antibiotics resistance genes (Dortetet al., 2013). The results of the search for plasmid resistance genes in Salmonella and Shigella strains indicate the absence or non-detection of the mcr-1 and mcr-2 genes in this work. These results may have several explanations. The first explanation would the fact that colistin resistance in Gram-negative bacteria is mainly due to the acquisition of mutations in two-component systems (Poirel et al., 2017). Investigation of the origin of colistin resistance in $30 E$. coli mcr-1 negative strains found that 22 strains carried amino acids in Pmrb, Phop, Phoq, Mgrb and/or Pmrd, while no mutation in any of these genes were found in the remaining eight isolates (Kim et al., 2019). In addition, several studies showed that the acquisition of $m c r$ plasmid genes is more prevalent in clinical $E$. coli strains (Sperandeo et al., 2007; Zhang et al., 2019). In addition, the prevalence of mcr-1 strains is low at $1.4 \%$ and $0.7 \%$ for clinical strains of $E$. coli and $K$. pneumoniae respectively (Yu et al., 2015). The prevalence of mcr-1 strains is low in humans compared to animals (Haenni et al., 2016). These bacteria (Padilla et al., 2010) would likely use other colistin resistance mechanisms such as synthesis or expression of efflux pumps. Ultimately, a 
decrease in the net negative charge of the outer membrane, lipid A loss or efflux pumps cause colistin resistance.

\section{CONCLUSION AND APPLICATION OF RESULTS}

This study showed that Salmonella and Shigella isolated from diarrheal faeces were resistant to colistin, a molecule of the last therapeutic line. This resistance to colistin in the city of Koula-Moutou is thought to be mediated by chromosomal and non-plasmid alterations. For better discrimination of molecular resistance, it

\section{RÉFÉRENCES}

Adelowo, O. O., Fagade, O. E. and Agers $\varnothing$, Y. (2014) 'Antibiotic resistance and resistance genes in Escherichia coli from poultry farms, southwest Nigeria', Journal of Infection in Developing Countries, 8(9), pp. 1103-1112. doi: 10.3855/jidc.4222.

Adriano Savoia Morales 1, Juliana Fragoso de Araújo, Vasco Túlio de Moura Gomes, Adrienny Trindade Reis Costa, Dália dos Prazeres Rodrigues, Thais Sebastiana Porfida Ferreira, Pedro Henrique Nogueira de Lima Filsner, Maria Roberta Felizardo, Andrea Micke Moreno (2012) 'The scientific World JOURNAL Colistin Resistance in Escherichia coli and Salmonella enterica Strains Isolated from Swine in Brazil', The Scientific World Journal, 2012, pp. 4-7. doi: 10.1100/2012/109795.

Ahmed Hasanin, Akram Eladawy, Hossam Mohamed, Yasmin Salah Ibrahim, Ahmed Lotfy, Hanan Mostafa; Doaa Ghaith, Ahmed Mukhtar (2014) 'Prevalence of extensively drug-resistant gram negative bacilli in surgical intensive care in Egypt', Pan African Medical Journal, 19, pp. 1 7. doi: 10.11604/pamj.2014.19.177.4307.

Ayalu A, R. et al. (2011) 'Antibiotic susceptibility patterns of Salmonella and Shigella isolates in Harar, Eastern Ethiopia', Journal of Infectious Diseases and Immunity, 3(8), pp. 134-139.

Cattoir, V. (2013) 'Infections caused by resistant gramnegative bacilli: New molecules and combinations', Journal des Anti-Infectious. Elsevier Masson SAS, 15(4), pp. 159-165. doi : 10.1016/j.antinf.2013.09.001.

Doit, C. (2015) 'Bactéries hautement résistantes émergentes en pédiatrie', Reanimation, 24(6), pp. 749-754. doi : 10.1007/s13546-015-11089.

Dortet, L. et al. (2016) 'Émergence De La Résistance À would be appropriate to screen all variants of the $\mathrm{mcr}$ gene as well as the determinants of chromosomal resistance. The results of this study provide a strong signal for monitoring the emergence of colistin resistance of enteric pathogens in Gabon.

La Colistine Chez Les Entérobactéries: Une Brèche Dans Le Dernier Rempart Contre La Pan-Résistance !', Journal des Anti-Infectieux. Elsevier Masson SAS, 18(4), pp. 139-159. doi : 10.1016/j.antinf.2016.09.003.

Dortet, L., Poirel, L. and Nordmann, P. (2010) 'Epidémiologie, Détection et Identification des Entérobactéries Productrices De Carbapénèmases', Enterobacterie o-new feuillets int, 312(January), pp. 1-12.

Dortet, L., Poirel, L. and Nordmann, P. (2013) 'Épidémiologie, détection et identification des entérobactéries productrices de carbapénèmases', Feuillets de Biologie, 312, pp. 1-13.

Emma Padilla, Enrique Llobet, Antonio DoménechSánchez, Luis Martínez-Martínez, José Antonio Bengoechea, Sebastián Albertí (2010) 'Klebsiella pneumoniae AcrAB Efflux Pump Contributes to Antimicrobial Resistance and Virulence', Antimicrobial Agents and Chemotherapy, 54(1), pp. 177-183. doi: 10.1128/AAC.00715-09.

EUCAST (2020) European Committee on Antimicrobial Susceptibility Testing Breakpoint tables for interpretation of MICs and zone diameters, version 10.0.

Frye, J. G and Jackson, C. R Genetic mechanisms of antimicrobial resistance identified in Salmonella enterica, Escherichia coli, and Enteroccocus spp. isolated from U.S. food animals, Frontiers in Microbiology, 4(135), pp. 1-22.

Gales, A. C., Jones, R. N. and Sader, H. S. (2011) 'Contemporary activity of colistin and polymyxin $B$ against a worldwide collection of Gramnegative pathogens: Results from the SENTRY antimicrobial surveillance program (2006-09)', Journal of Antimicrobial Chemotherapy, 66(9), 
pp. 2070-2074. doi: 10.1093/jac/dkr239.

Huimin Zhang, Swaminath Srinivas, Yongchang Xu, Wenhui Wei, Youjun Feng (2019) 'Genetic and Biochemical Mechanisms for Bacterial Lipid A Modifiers Associated with Polymyxin Resistance', Trends in Biochemical Sciences. Elsevier Inc., 44(11), pp. 973-988. doi: 10.1016/j.tibs.2019.06.002.

Jean Fabrice Yala, Rolande Mabika Mabika, Franck Mounioko, Ornella Zong Minko, Alexis Nicaise Lepengue, Alain Souza. (2020) 'In Vitro Antibacterial Activity of an Aqueous Extracts of the Tephrosia Vogelii Hook. F Combined To Imipenem on E. coli Strains', scholars Academic Journal of Pharmacy, 9531, pp. 110. doi: 10.36347/sajp.2020.v09i01.00X.

Jilei Zhang, Li Chen, Jiawei Wang, Afrah Kamal Yassin, Patrick Butaye, Patrick Kelly, Jiansen Gong, Weina Guo, Jing Li, Min Li, Feng Yang, Zhixing Feng, Ping Jiang, Chunlian Song, Yaoyao Wang, Jinfeng You, Yi Yang, Stuart Price, Kezong Qi, Yuan Kang \& Chengming Wang (2018) 'Molecular detection of colistin resistance genes (mcr-1, mcr-2 and mcr-3) in nasal / oropharyngeal and anal / cloacal swabs from pigs and poultry', Scientific Reports. Springer US, 8(3705), pp. 1-9. doi: 10.1038/s41598-018-22084-4.

L. Dorteta, R. Bonnina,, A. Jousseta, L. Gauthiera,T. Naas. (2016) 'Émergence de la résistance à la colistine chez les entérobactéries : une brèche dans le dernier rempart contre la panrésistance !', Journal des Anti-infectieux, 18(4), pp. 139-159. doi: https://doi.org/10.1016/j.antinf.2016.09.003.

Laura M. Lamberti, A. Louis Bourgeois, Christa L. Fischer Walker, Robert E. Black, David Sack. (2014) 'Estimating Diarrheal Illness and Deaths Attributable to Shigellae and Enterotoxigenic Escherichia coli among Older Children, Adolescents, and Adults in South Asia and Africa', 8(2), pp. 1-7. doi: 10.1371/journal.pntd.0002705.

Marisa Haenni , Laurent Poirel , Nicolas Kieffer , Pierre Châtre, Estelle Saras, Véronique Métayer, Romain Dumoulin , Patrice Nordmann , JeanYves Madec (2016) 'Correspondence Cooccurrence of extended spectrum $\beta$ lactamase and MCR-1 encoding genes on plasmids', Lancet Infect Dis., 16(3), pp. 281-282. doi: 10.1016/S1473-3099(16)00007-4.
Mohammadmahdi Karimi-Yazdi 1, Zohreh Ghalavand 1, Mahdi Shabani 2, Hamidreza Houri 3, Mehrzad Sadredinamin 1, Marzieh Taheri 1, Gita Eslami 1 (2020) 'High Rates of Antimicrobial Resistance and Virulence Gene Distribution Among Shigella spp . Isolated from Pediatric Patients in Tehran, Iran', Infection and Drug Resistance, 13, pp. 485-492.

Nordmann, P., Dortet, L. and Poirel, L. (2012) 'Carbapenem resistance in Enterobacteriaceae: Here is the storm! Carbapenem resistance in Enterobacteriaceae : here is the storm !' Trends in Molecular Medicine. Elsevier Ltd, (April). doi: 10.1016/j.molmed.2012.03.003.

Paola Sperandeo, Rachele Cescutti, Riccardo Villa, Cristiano Di Benedetto, Daniela Candia, Gianni Dehò, Alessandra Polissi (2007) 'Characterization of IptA and IptB, Two Essential Genes Implicated in Lipopolysaccharide Transport to the Outer Membrane of Escherichia coli', 189(1), pp. 244253. doi: 10.1128/JB.01126-06.

Poirel, L., Jayol, A. and Nordmanna, P. (2017) 'Polymyxins: Antibacterial Activity, Susceptibility Testing, and Resistance Mechanisms Encoded by Plasmids or Chromosomes', Clinical Microbiology, 30(2), pp. 557-596.

Robin, F., Gibold, L. and Bonnet, R. (2012) 'Résistances naturelles et acquises aux $\beta$-lactamines chez les entérobactéries : comment les identifier en pratique quotidienne?', Revue Francophone des Laboratoires. Elsevier, 2012(445), pp. 4758. doi: 10.1016/S1773-035X (12)71676-3.

Rolande Mabika, Sandrine Lydie Oyegue Liabagui, Franck Mounioko, Marie Gabrielle Moussavou, Joseph Marie Odzame Affiri, Alain Souza, Jean Fabrice Yala (2019) 'Study of the sensitivity to carbapenems the Escherichia coli isolated from childhood diarrhoea at the Paul Moukambi Hospital center of Koula-Moutou', International Journal of Innovation Sciences and Research, 8(6), pp. 1411-1417.

S. Mezghani Maalej, M. Rekik Meziou, F. Mahjoubi, A. Hammami (2012) 'Epidemiological study of Enterobacteriaceae resistance to colistin in Sfax (Tunisia)', Medicine et Maladies Infectieuses. Elsevier Masson SAS, 42(6), pp. 256-263. doi: 10.1016/j.medmal.2012.04.008.

Shukho Kim, Jung Hwa Woo, Nayeong Kim, Mi Hyun 
Kim, Se Yeon Kim, Joo Hee Son, Dong Chan Moon, Suk-Kyung Lim, Minsang Shin, and Je Chul Lee1 (2019) 'Characterization of Chromosome-Mediated Colistin Resistance in Escherichia coli Isolates From Livestock in Korea', Infection and Drug Resistance, 12, pp. 3291-3299.

Sue C Nang 1, Mei-Ling Han 1, Heidi H Yu 1, Jiping Wang 1, Von Vergel L Torres 1, Chongshan Dai 2, Tony Velkov 3, Marina Harper 1, Jian Li 1 (2019) 'Polymyxin resistance in Klebsiella pneumoniae : multifaceted mechanisms utilized in the presence and absence of the plasmidencoded phosphoethanolamine transferase gene mcr-1', J Antimicrob Chemother, pp. 1-9. doi: 10.1093/jac/dkz314.

Sun S, Negrea A, Mikael Rhen, Andersson DI (2009) 'Genetic Analysis of Colistin Resistance in Salmonella enterica', Antimicrobi. Agents. Chemother, 53(6), pp. 2298-2305. doi : 10.1128/AAC.01016-08.

Yi Yuan , Ying Li , Guangxi Wang , Chengwen Li , Li Xiang , Junping She, Yan Yang, Fangcai Zhong, Luhua Zhang (2019) 'Coproduction Of MCR-9 And NDM-1 By Colistin-Resistant Enterobacter hormaechei Isolated From Bloodstream Infection', Infection and Drug Resistance, 12(2979-2985).

Zhiliang Yu, Wangrong Qin, Jianxun Lin, Shisong Fang, and Juanping Qiu (2015) 'Antibacterial Mechanisms of Polymyxin and Bacterial Resistance', (January). doi: 10.1155/2015/679109. 